\title{
Beta-ketothiolase deficiency
}

INSERM

\section{Source}

INSERM. (1999). Orphanet: an online rare disease and orphan drug data base. Betaketothiolase deficiency. ORPHA:134

Beta-ketothiolase (T2) deficiency is a rare organic aciduria (see this term) affecting ketone body metabolism and the catabolism of isoleucine and characterized by intermittent ketoacidotic episodes associated with vomiting, dyspnea, tachypnoea, hypotonia, lethargy and coma, with an onset during infancy or toddlerhood and usually ceasing by adolescence. 